\title{
Sequências Didáticas de Caráter Sociocientífico como Espaço de Pesquisa, Formação e Ensino na Interface Escola-Universidade
}

\section{Socio-scientific Didactic Sequences as a Space of Research, Education and Teaching in the School-University Interface}

\author{
iD Lizete Maria Orquiza-de-Carvalho ${ }^{1}$ \\ Laise Vieira Gonçalves ${ }^{1}$ \\ Daisi Teresinha Chapani²
}

\begin{abstract}
'Universidade Estadual Paulista (UNESP), Faculdade de Ciências, Programa de Pós-Graduação em Educação para a Ciência, Bauru, SP, Brasil. Autora correspondente: lizete.orquiza-carvalho@unesp.br

${ }^{2}$ Universidade Estadual do Sudoeste da Bahia (UESB), Programa de Pós-Graduação em Educação Científica e Formação de Professores, Jequié, BA, Brasil.
\end{abstract}

Resumo: Neste artigo analisamos o processo de produção de sequências didáticas de caráter sociocientífico em um contexto de ação e formação de professores na interface escolauniversidade. Indagamos sobre a maneira e as condições em que o caráter controverso do conhecimento científico e tecnológico foi evidenciado em diferentes processos de formulação de questões sociocientíficas durante o planejamento de sequências didáticas ocorrido no âmbito escola-universidade. Os dados foram constituídos a partir de teses e dissertações produzidas em um mesmo grupo de pesquisa. Como resultado, foram evidenciadas etapas de desenvolvimento do trabalho coletivo em função de desdobramentos do debate sobre as questões sociocientíficas.

Palavras-chave: Formação de professores; Sequências didáticas; Questões sociocientíficas; Integração escola-universidade.

Abstract: In this article we analyze the production process of socio-scientific didactic sequences in a context of teacher action and education in the school-university interface. We inquired about the manner and conditions in which the controversial character of scientific and technological knowledge was evidenced in different socio-scientific issue formulation processes during the planning of didactic sequences taking place in the school-university scope. The data consist from theses and dissertations produced within a research group. As a result, the developmental stages of collective work stages were evidenced, which depended on the outcomes of the discussions of socio-scientific issues.

Keywords: Teacher training; Didactic sequences; Socio-scientific issues; School-university integration.

Recebido em: 05/08/2020

Aprovado em: 21/12/2020 


\section{Introdução}

Este artigo tem como base o conhecimento produzido por meio de um conjunto de atividades teórico-práticas desenvolvidas no âmbito do grupo de pesquisa Educação Continuada de Professores e Avaliação Formativa, conhecido pelos participantes como AVformativa, sediado na Universidade Estadual Paulista (UNESP). Entre as atividades do grupo, há permanentemente o desenvolvimento de projetos conjuntos, os quais têm se organizado em uma estrutura que interconecta dois níveis: um denominado Pequeno Grupo de Pesquisa (PGP) e outro conhecido como Grande Grupo de Pesquisa (GGP). Situado na escola, o PGP é o lugar de constante problematização da prática educacional, o que se dá a partir de dentro das instituições de educação básica. Por outro lado, o GGP é o lugar de encontro dos PGP e, por isso, de contínuo questionamento do trabalho de sustentação das interações concretas entre eles, o que se dá a partir de fora das instituições de educação básica e superior. Estas interações têm se constituído como uma construção coletiva e permanente, tanto no plano prático quanto teórico.

Os dois construtos interconectados (PGP-GGP) organizam-se em torno de três balizadores do processo coletivo de sua consolidação mútua: (i) interação entre escola e universidade, por meio de pesquisa colaborativa nos campos da formação de professores entendida como investigação-ação crítica; (ii) construção de sequências didáticas baseadas na formulação e desenvolvimento de questões sociocientíficas (QSC); e, (iii) consideração do enquadramento das políticas públicas sobre a formação de professores e currículo.

Decorre disso que a formação dos professores e o desenvolvimento de sequências didáticas de caráter sociocientífico não são percebidos pelas autoras deste artigo como categorias estanques. Isso remete-nos a Giroux (1997), para quem há necessidade de desenvolvimento de uma linguagem a qual educadores consigam "[...] desvelar e compreender o relacionamento entre ensino escolar, as relações sociais mais amplas que o informam, e as necessidades e competências historicamente construídas que os estudantes trazem para as escolas" (GIROUX, 1997, p. 10).

Entendendo que, na modernidade, a realidade social é fortemente marcada pela Ciência e Tecnologia e que, conforme Martínez-Pérez e Carvalho (2012), os professores de ciências não têm sido apropriadamente preparados para o tratamento de temas públicos relacionados ao progresso científico e tecnológico. Concordamos com estes autores quando advogam pela abordagem de questões sociocientíficas como "[...] forma de tratar, na prática dos professores, temas como natureza da ciência e da tecnologia, raciocínio ético-moral, reconstrução sociocrítica, ação responsável e sustentabilidade" (MARTÍNEZ-PÉREZ; CARVALHO, 2012, p. 729).

Nesse sentido, a inserção de questões sociocientíficas tem se mostrado uma abordagem interessante uma vezque elas abrangem controvérsias que, consideravelmente, envolvem "[...] implicações sociais, econômicas, religiosas, científicas, tecnológicas, políticas e ambientais que podem ser trabalhados em aulas de ciências com o intuito de favorecer a participação ativa dos estudantes em discussões escolares que enriqueçam seu crescimento pessoal e social" (MARTINEZ PERÉZ; CARVALHO, 2012, p. 729).

Desse modo, ao propor a formação coletiva e interdisciplinar dos professores e alunos da escola básica por meio das QSC, o construto PGP-GGP opera como uma prática ativo-investigativa, que pode ser compreendida por meio do conceito de professor 
como intelectual transformador (GIROUX, 1997), que é aquele professor que, sabendo de todas as amarras, busca agir no sentido de enfraquecer as forças hegemônicas, interagindo com os grupos para envolver as culturas e tradições emancipatórias dentro e fora da esfera pública. Saber de tais amarras consiste em poder reconhecer como a cultura escolar dominante está implicada nas práticas hegemônicas, que, muitas vezes, além de silenciar os grupos subordinados de estudantes, incapacitam e desautorizam aqueles que Ihes ensinam. Assim, para o autor, é importante descortinar aos olhos dos professores, alunos e demais integrantes da escola, os interesses capitalistas que subjazem ao empreendimento científico e tecnológico, permitindo-se assim a crítica e a indignação perante a barbárie.

Diante desse quadro, buscamos compreender a maneira e as condições em que o caráter controverso do conhecimento científico e tecnológico foi evidenciado em formulações de diferentes questões sociocientíficas, no contexto de sequências didáticas planejadas por grupos de professores no âmbito do PGP-GGP.

\section{O Cenário da Pesquisa: o processo de constituição dos PGP e GGP}

A origem dos termos PGP e GGP em nossos estudos pode ser identificada em um projeto de parceria entre universidade e escola, que teve início no ano de 2000 e durou 6 anos, envolvendo o corpo docente de uma escola pública de ensino médio e cerca de 10 professores da universidade: pesquisadores em áreas de ciências, matemática, língua portuguesa e ensino de ciências. Em determinado momento do processo ativoinvestigativo subjacente, chegou-se à seguinte compreensão: o trabalho em grupos com os professores, seguido de plenárias para discussão das propostas trazidas pela universidade, deveria se transformar em um modelo de pequenos grupos com identidade definida, para fins de estudo e pesquisa.

Assim, o desenvolvimento dos projetos comuns realizados no grupo AVformativa passou por diversas fases, envolvendo várias instituições, e contou com financiamento da Fundação de Amparo à Pesquisa do Estado de São Paulo (FAPESP), entre 2002 e 2005, e da Coordenação de Aperfeiçoamento de Pessoal de Nível Superior (CAPES), por meio do Programa Observatório da Educação (Obeduc), entre 2011 e 2015. Durante o primeiro projeto citado, foram constituídos 8 PGP em uma única escola de educação básica, envolvendo diferentes campi de uma universidade, ao passo que, no segundo projeto, foram constituídos 18 PGP, cada um em uma escola pública diferente, envolvendo três universidades: UNESP, Universidade Estadual do Mato Grosso e a Universidade Federal do Mato Grosso. Os resultados das discussões, das práticas e das pesquisas produzidas nesse processo estão apresentados em uma extensa produção acadêmica, da qual utilizaremos aqui apenas alguns exemplos que consideramos mais ilustrativos.

Nesse processo, diversos estudos, como por exemplo o de Martinez (2009), colaboraram para que o grupo avançasse em sua compreensão teórica a respeito de uma determinada concepção de formação de professores, que não abre mão da perspectiva dialógica, ou seja, subjaz a ela uma suposição de que não há formação a não ser na condição de reciprocidade nos processos formativos dos envolvidos aliada a uma concepção de pesquisa comprometida com transformação social. Para além disso, a partir da perspectiva bourdieana, um caráter de estrutura pôde ser atribuído à rede de PGP, significando que ela se assentava como um conjunto de práticas regulares e 
continuamente reguladas, às quais subjaziam princípios, de modo que guardava, nas suas relações internas e externas, a potencialidade de gerar novas práticas e novas representações na intersecção dos seus campos de origem (FREITAS, 2008).

Assim, se estávamos de posse de um conjunto de conhecimento e fazeres compreendido como novos habitus constituídos pelos agentes na interface universidade-escola, poderíamos tomá-lo como saber inicial para a abrir novamente o leque de questões que seguiam nos interessando enquanto investigadores ativos. Desta forma, no contexto do projeto do Obeduc, posto em marcha em diálogo perene com participantes da escola e da universidade, novas compreensões sobre a rede de PGP foram efetivadas. Uma primeira compreensão fundamental foi proporcionada por uma nova disposição para elaborar, dentro da rede de PGP, um conhecimento e uma prática mais sólidos sobre o fazer coletivo de preparação e realização de sequências didáticas pelos professores. Nesse contexto, consideramos como sequências didáticas um conjunto de atividades que visa à realização de finalidades e intenções educacionais as quais "[...] constituem o ponto de partida primordial que determina, justifica e dá sentido à intervenção pedagógica" (ZABALA, 1988, p. 21), permitindo aos estudantes realizarem apropriação cultural por meio de uma sucessão de questionamentos próprios.

Dessa forma, a abordagem sociocientífica foi assumida, em vários grupos, para orientar a preparação e discussões conjuntas das aulas na escola As questões sociocientíficas são valorizadas no cenário educacional pelo seu grande potencial para a problematização da influência que a ciência e a tecnologia exercem na nossa sociedade contemporânea, sendo percebidas como vigorosas para orientar o desenvolvimento das sequências didáticas para o tratamento dos conteúdos disciplinares como para a construção de currículos locais. Segundo Martínez- Pérez e Carvalho (2012, p. 729),

[...] as QSCs abrangem controvérsias sobre assuntos sociais que estão relacionados com conhecimentos científicos da atualidade e que, portanto, em termos gerais, são abordados nos meios de comunicação de massa (rádio, TV, jornal e internet). Questões como a clonagem, a manipulação de células tronco, os transgênicos, o uso de biocombustíveis, a fertilização in vitro, os efeitos adversos da utilização da telecomunicação, a manipulação do genoma de seres vivos, o uso de produtos químicos, entre outras, envolvem consideráveis implicações científicas, tecnológicas, políticas e ambientais que podem ser trabalhadas em aulas de ciências com o intuito de favorecer a participação ativa dos estudantes em discussões escolares que enriqueçam seu crescimento pessoal e social.

Pudemos também reconhecer que, a partir das questões sociocientíficas, a rede de PGP favorecia o desenvolvimento de processos argumentativos de um modo geral, bem como o aumento das capacidades argumentativas, consideradas a partir de um referencial filosófico e sociológico mais amplo (HABERMAS, 2002). Assim, para Lopes (2013), o fato de assumirmos a comunicação como entendimento e consenso tem orientado as práticas desenvolvidas pelos PGP, cabendo à Educação em Ciências "[...] a possibilidade de formar agentes éticos e voltados para o exercício da crítica e da argumentação no interior das esferas públicas" (LOPES, 2013, p. 51).

Uma segunda compreensão, advinda do trabalho com as sequências didática de caráter sociocientífico foi a de que a rede de PGP tem potencialidade para dar corporeidade ao reconhecimento dos professores como produtores 
culturais (ORQUIZA-DE-CARVALHO; CARVALHO; LOPES JUNIOR, 2019). Segundo Santos e Carnio (2019, p. 15), "[...] é representativo da práxis reconhecer os professores enquanto produtores de cultura, tornando o espaço tensionado, múltiplo, carregado de idiossincrasias típicas do que é a própria formação de professores concebida na interface Universidade-Escola". Nesse sentido, pudemos reconhecer que sua potência se estende ao desenvolvimento da autonomia de professores diante do trabalho pedagógico e à formação crítica e cidadã dos alunos (SANTOS; CARNIO; MENDONÇA, 2016). Neste projeto, a temática liga-se a um referencial mais largo, a Teoria da Ação Comunicativa (HABERMAS, 2002), por meio das sequências didáticas, quando, então, ganha sentido afirmar que:

[...] os temas de investigação são buscados nas esferas do mundo da vida - cultura, sociedade e personalidade, o que significa que o grupo se constitui como um lugar de luta incansável pelo pleno sentido para uma conversa aberta sobre os vários níveis de realidade reconhecidos conjuntamente pelos integrantes da universidade e da escola, em contextos concretos, incluindo aí o reconhecimento e a legitimação da história de vida dos envolvidos (ORQUIZA-DE-CARVALHO, 2016, p. 10).

Quanto à validade do trabalho dos grupos na área de formação de professores de ciências, Pedrancini e Sierra (2016, p. 45) identificam avanços e rupturas com a perspectiva tradicional, tais como:

[...] autonomia e emancipação docente; problematização do papel do professor na sociedade e de sua prática, bem como do sistema educacional; desenvolvimento da argumentação; leitura mais humanística do campo científico; resgate do potencial da comunicação e do trabalho coletivo.

As autoras defendem também que os limites e obstáculos gerados precisam ser considerados e problematizados, a citar os fatores: tempo, influência da racionalidade técnica nos modelos de formação, predomínio da racionalidade sistêmica na escola, resistência às estratégias diferenciadas de formação, dentre outros. Nesse sentido, as possibilidades da interface entre a formação e as QSC poderiam ser atingidas em sua totalidade. Entretanto, tal fato não é entendido propriamente como limitação, mas sim como "[...] um indício de que o tratamento de QSC em uma perspectiva crítica, para sustentar uma coerência e assumir uma postura de transformação do contexto e de promoção de tensões e inquietações, demanda tempo, continuidade e cuidado constante com o processo" (SANTOS, 2013, p. 193).

\section{O Corpus da Pesquisa: a elaboração e a realização de sequências didáticas nos PGP}

Neste item, buscamos evidenciar possíveis relações entre o trabalho dos PGP e a qualidade e o caráter das sequências didáticas ali desenvolvidas. Para tanto, consideramos um conjunto de 5 teses e 2 duas dissertações desenvolvidas no âmbito do Projeto Obeduc, elegendo três desses trabalhos conforme o critério de acessibilidade às descrições das sequências didáticas de caráter sociocientífico que foram desenvolvidas nos PGP em questão. 


\section{PGP Arealva}

Quanto ao PGP situado em uma escola pública de Arealva, SP, consideramos aqui duas etapas de trabalhos (LENHARO et al., 2019). A primeira foi marcada pelas seguintes características: coordenação realizada por um professor da escola participante ativo do grupo AVformativa, cujo cuidado intensivo e extensivo de convites para participação de colegas professores foi determinante para a constituição do PGP; participação de uma doutoranda e um mestrando do mesmo grupo; recepção conflituosa de um trabalho acadêmico que havia constituído dados de tese naquela escola; temática o uso de agrotóxicos na região de Arealva para constituição e desenvolvimento de sequências didáticas. Num primeiro momento, os encontros aconteciam no contra horário do calendário escolar e, num segundo momento, passaram a acontecer durante a Aula de Trabalho Pedagógico Coletivo (ATPC). A segunda fase foi marcada pelos seguintes aspectos: coordenação de outro professor da escola, não inicialmente alinhado ao grupo AVformativa; ingresso de muitos professores da escola ao grupo; pela integração de novos pós-graduandos do grupo de pesquisa; incorporação do PGP como espaço de formação continuada da escola; temática padrão de beleza, consumismo e saúde para constituição e desenvolvimento de sequências didáticas.

\section{PGP Arealva: o uso de agrotóxicos na região de Arealva-SP}

A primeira fase iniciou-se em maio de 2011 com discussões sobre problemas da escola e da cidade e sobre as diretrizes e eixos do Projeto. Isso se deu por meio do estudo conjunto de uma tese anteriormente desenvolvida nesta escola por um membro do GGP (GENOVEZ, 2008), o que causou significativo desentendimento na relação entre escola e universidade. No entanto, o enfrentamento da situação propiciou um ambiente de verdadeira conversa entre os dois segmentos.

\footnotetext{
Isso mexeu com todos, ocasionando interrogações, comentários, contradições e indisposições que, para serem entendidas de fato, tinham que ser estudadas. Logo surgiram outros questionamentos, como sobre o que estudar, como conduzir o grupo e como agir na escola (LENHARO et al., 2019, p. 69).
}

Como consequência, os participantes identificaram objetos de reflexão importantes: o contexto sociocultural e econômico em que estavam imersos, o modo de operar do grupo, a forma como eles se embasavam em conhecimentos reconhecidos e estudados nas universidades e a própria reflexão que faziam. Não demorou para que o ambiente de discussão sobre a realidade em que estavam imersos parecesse já potente no sentido de propiciar qualidade para as sequências didáticas que viriam a ser construídas nessa fase. Como ressalta Lopes (2013), esta discussão possibilitou que se levantasse as condições socioeconômicas e culturais da escola:

Então, foi possível o reconhecimento da necessidade de se trabalhar a QSC relacionada com a temática dos agrotóxicos, como retomada do mundo da vida da comunidade, de modo que a escola pudesse reconhecer, estudar e agir diante do problema, além disso, a escola refletiria sobre a formação para a ação de seus alunos que residem e trabalham na área rural (LOPES, 2013, p. 182). 
Podemos colocar como marco do início da elaboração das sequências didáticas no PGP a decisão conjunta de se levantar uma base sociocientífica sobre a qual se daria, de modo articulado, o trabalho coletivo do grupo e práticas dos professores nas salas de aula. Isso acabou gerando dois tipos de atitudes no grupo: compromisso com desvelamento da realidade cultural, social e econômica da escola e da cidade e disponibilidade para a abrangência e profundidade nos estudos, sobre um tema sociocientífico, educação problematizadora e abordagem CTSA. Paralelamente, houve maior liberdade para o enfrentamento de problemáticas surgidas na interação escolauniversidade (ARENGHI, 2014).

As propostas iniciais para temática sociocientífica que perpassaram as conversas foram: a questão das drogas entre os alunos da escola e os equipamentos de proteção individual (EPI) nos cultivos da lavoura na região. O tema dos agrotóxicos foi somente introduzido no sétimo encontro do grupo, trazido por professor de química que possuía um cultivo de hortaliças na cidade. Como o município de Arealva caracteriza-se por uma base econômica agropecuária, com uma parte expressiva da população vivendo na zona rural, havia relatos de problemas de saúde pública relacionados à compra, venda e uso inadequado desses produtos, além de intoxicação, doenças associadas etc.

Algumas diretrizes foram traçadas para o início dos trabalhos com as QSC como, por exemplo, maior cuidado com os alunos do período da tarde que, na sua maioria, eram provenientes da área rural da cidade e de que a QSC deveria emergir das questões geográficas do município. Nessa constelação de problemáticas, as consequências dos agrotóxicos para os alunos trabalhadores no campo e em estufas, em relação ao manuseio da calda, ganharam um lugar importante na leitura que os professores fizeram da realidade vivida. Um indicador desse estado de coisas pode ser encontrado em Lopes (2013, p. 186): "[...] claramente, os argumentos para o desenvolvimento da questão levam em conta as características das QSC, mas principalmente, o fato de pertencer à vida cotidiana da cidade fez com que os professores se envolvessem mais com a questão".

Em seguida, foram realizados estudos e estruturações teóricas sobre educação problematizadora e sobre a abordagem das QSC, tendo-se como contraponto os conhecimento adquiridos sobre o tema "agrotóxicos" (ARENGHI, 2014). Segundo Lopes (2013), durante tais estudos, posicionamentos conflitantes referentes à temática abordada foram identificados, acabando por permitir o levantamento de uma controvérsia entre os efeitos no corpo humano da exposição a agrotóxicos (toxidade) e os interesses da indústria agrária (custos).

Houve um período de explanação dos trabalhos de pesquisa desenvolvidos por professores da escola e da universidade. Os dois relatos que seguem abordam os mesmos acontecimentos de pontos de vista diferentes, o primeiro traz a voz do conjunto dos participantes do PGP e o segundo traz a voz de uma doutoranda inserida no grupo desde o seu início.

Professores de diversas disciplinas passaram a atuar em conjunto e trocavam experiências e informações com os alunos. O terceiro ano do ensino médio, por exemplo, lia livros na disciplina de língua portuguesa sobre as comunidades da época de Vargas, Silvana, a professora de História trabalhava elementos da Segunda Guerra Mundial, da Guerra do Vietnã, o agente laranja e seus efeitos, Bruno, o 
professor de Física junto ao Gilberto, professor de Biologia, e Flávio, professor de química, faziam cálculos sobre proporções químicas e estudavam rótulos dos agrotóxicos, de modo que iniciamos um intenso diálogo entre as matérias (LENHARO et al., 2019, p. 70-71).

Nas palavras de Lopes (2013, p. 149):

Outras apresentações representaram o desenvolvimento do trabalho do grupo em
termos da elaboração e discussão das sequências didáticas relacionadas à temática
dos agrotóxicos, que foram realizadas com os alunos do ensino médio. Nestas
exposições, os professores apresentaram suas propostas de trabalho, com os
assuntos e conceitos a serem abordados, além das metodologias propostas. Assim,
os professores tinham contato com as propostas dos colegas e cuidavam para não
desenvolver atividades semelhantes, uma vez que as salas de aula trabalhadas eram
as mesmas. Também ocorria o compartilhamento de informações e discussões
acerca dos resultados expressos pelos alunos, por meio das avaliações e portfólios.

Arenghi (2014) permite-nos visitar um desses planejamentos: o de física. Neste caso específico, tratou-se de uma parceria entre dois licenciados em física da Unesp de Ilha Solteira, um deles, professor da escola e coordenador do PGP, e outro, estudante de mestrado cuja dissertação foi constituída e desenvolvida no grupo. O mestrando já trazia do contexto acadêmico da pós-graduação a intenção de abordar a questão sociocientífica do ponto de vista da divulgação científica. A partir daí, o entendimento entre os dois, ocorrido por meio de intenso diálogo, definiu o caminho dos trabalhos, que se iniciaria com "[...] uma vasta pesquisa foi feita em bancos de dados, bibliotecas e páginas de internet, buscando textos de divulgação científica que apresentassem a temática 'agrotóxicos'" (ARENGHI, 2014, p. 56, grifo do autor).

Preocupado com o cumprimento da sua carga didática, o professor demarcou o número de seis aulas que poderia ceder para a realização da sequência, porém, no decorrer do processo, ele mesmo propôs que esse tempo fosse estendido. De fato, durante as aulas, atuaram como dupla efetiva de docentes, sendo assim reconhecidos pelos alunos. No que concerne ao conteúdo científico subjacente (modelos atômicos), cuja escolha dependeu da busca de adequação da temática sociocientífica ao currículo escolar, a reflexão de planejamento foi guiada pela seguinte questão: "[...] como congregar as possibilidades formativas da divulgação científica e a introdução do conhecimento cientifico relacionado a modelos atômicos sem que a interação a sala de aula retomasse o padrão dos modelos tradicionais de ensino de Física?" (ARENGHI, 2014, p. 57).

Dois textos foram eleitos para serem levados para a sala de aula. O primeiro era um artigo publicado em janeiro de 2012 na Revista Veja com o título de $A$ verdade sobre os agrotóxicos, que reinterpretava os dados da Agência Nacional de Vigilância Sanitária (ANVISA) e alertava o leitor sobre o fator de menor risco em relação ao consumo de alimento (O QUE..., 2012). No entanto, este texto expressava uma opinião pró-indústria, ou seja, era não somente favorável ao uso de agrotóxicos, como também excluía possíveis vieses concorrentes. O segundo referia-se a uma entrevista concedida pelo médico e pesquisador em saúde pública da Universidade Federal do Mato Grosso, Wanderlei Antônio Pignati, à Revista Galileu (PIGNATI, 2010), cujo teor era a 
problemática dos agrotóxicos capturada do ponto de vista das consequências destes para vida dos trabalhadores nas plantações.

Na primeira parte da sequência didática (duas aulas), os alunos, organizados em grupos, realizaram leitura e discussão de um texto e, em seguida, apresentaram uma síntese das ideias consideradas relevantes por eles. Para a sequência, os professores propuseram a confecção de um artigo de opinião para ser feito em casa e entregue na aula seguinte. Depois dessas duas rodadas, foi aberta uma discussão ampla sobre as pretensões da divulgação científica e da ciência.

A despeito de que o foco deste trabalho esteja na preparação de sequências didáticas, considerar o que efetivamente ocorreu na aula (ARENGHI, 2014) pode ser interessante. De fato, durante a efetivação dessa discussão, todos alunos, inclusive aqueles que no início estiveram calados, envolveram-se fortemente. Notamos, assim, que a experiência de liberdade argumentativa sobre o tema sociocientífico, vivida no PGP pelos professores, no primeiro estágio do planejamento, pôde ser proporcionada aos alunos do ensino médio. Do ponto de vista da preparação de aula, entendemos que a consideração de uma questão sociocientífica pelos alunos necessita vivência anterior dos professores, de modo que a familiaridade deles com os diferentes aspectos da QSC os auxiliem a permitir o posicionamento sincero dos alunos, de tal modo que valores éticos e morais possam emergir na sala de aula.

A segunda parte da sequência didática voltou-se para a inserção dos conteúdos curriculares referentes à ciência, iniciando-se com o estudo do modelo atômico. Este seria introduzido a partir da análise dos fenômenos físicos ocorridos no bico da bomba de aplicação dos agrotóxicos e, também, da leitura e interpretação da bula de um agrotóxico, uma vez que ela possui valores numéricos, referentes aos volumes da substância, cita unidades de medida e contém termos científicos. A partir destas atividades, os professores conduziriam uma aproximação entre QSC e o conteúdo curricular por meio da consideração do tamanho das moléculas. Entendendo como conteúdo da sequência didática tanto o produto do trabalho científico como o contexto de produção da ciência, nas aulas seguintes, realizaram um estudo, a partir da leitura conjunta, de um texto sobre história e natureza da ciência, com o objetivo de permitir que eles reconhecessem novos aspectos do conhecimento científico.

A terceira parte, por sua vez, tinha como objetivo a expressão de uma ação cidadã pelos grupos de alunos, que foram chamados a confeccionar um material instrucional do tipo folder, sobre o tema agrotóxico, para ser distribuído nas propriedades rurais da região. Do ponto de vista da avaliação do trabalho dos alunos, a confecção do folder teve como meta esclarecer o entendimento que estes tiveram sobre as componentes estruturais da sequência didática, de modo a possibilitar a articulação de concepções sobre ciência, divulgação científica, conhecimento científico e outros temas desenvolvidos.

\section{PGP Arealva: padrão de beleza, consumismo e saúde}

A segunda fase mencionada foi investigada por Carnio (2017), que buscou delinear aspectos formativos do trabalho de constituição e desenvolvimento de uma QSC pelos professores do PGP. Nesse momento, o grupo já tinha conquistado visibilidade perante a escola, o que pode ser notado pela fala de uma professora: 
Quando no fim do ano a [coordenadora do PGP] apresentou o trabalho dos alunos, e que eu vi todo aquele pacote de trabalhos que ela trouxe numa reunião, acho que foi no planejamento [...], e eu comecei a ver os alunos que tinham elaborado aqueles trabalhos e foram alunos meus que eu achava que eram muito limitados. $E$, no entanto, quando eu vi aquela extensão, aquele trabalho enorme, aquele trabalho maravilhoso, eu fiquei assim babando pelo PGP. Foi aí que eu comecei a mudar a minha visão diante o PGP. [...] Aí eu vi toda uma sequência didática, e eu não tinha uma noção ampla de sequência didática, e eu comentei com a [coordenadora do PGP], eu aprendi muito sobre sequência didática por meio do PGP (LENHARO et al., 2019, p. 72).

O trabalho com as sequências didáticas no início de 2013 iniciou-se por meio de duas expectativas compartilhadas no PGP: de que o trabalho coletivo interdisciplinar contribuísse com a busca de melhores índices da escola nas avaliações em larga escala e que a etapa de formulação de uma nova QSC levasse a "[...] uma questão concreta do contexto dos alunos" (LENHARO et al., 2019, p.73). Assim, a temática dos problemas alimentares entre os alunos (bulimia, anorexia, maus hábitos alimentares, consumo excessivo de sal e gordura, entre outros) acabou por se mostrar de grande fertilidade, pois, muitos casos foram relatados. A partir dessa reflexão conjunta, acabaram chegando ao seguinte tema para a QSC: padrão de beleza, consumismo e saúde. A isso seguiu-se uma série de estudos e discussões sobre questões sociocientíficas, interdisciplinaridade e sistemas de avaliação em larga escala (CARNIO, 2017). Ao final deste estudo, produziram o consenso de que o caráter sociocientífico que orientaria as sequências didáticas deveria ser articulado com as demandas curriculares de cada disciplina. A isso seguiu-se a eleição de turmas nas quais as sequências seriam desenvolvidas. Segundo Carnio (2017, p. 140), "[...] uma das demandas agregadas ao grupo foi a busca por melhores índices (principalmente matemática e português) por parte da escola como um todo, o que foi fator determinante para a escolha das turmas a serem destinadas a QSC."

A decisão seguinte foi a de que o Currículo do Estado de São Paulo e o Caderno do Professor seriam utilizados como material balizador para o embasamento disciplinar. Como tarefa conjunta, estabeleceram que haveria uma série de apresentações, no PGP, feitas pelos professores das diferentes disciplinas, sobre possibilidades de reconhecimento da QSC nos materiais curriculares de suas áreas de conhecimento. Nessa perspectiva, os conteúdos deveriam ser relacionados a hábitos de vida, aspectos culturais, influência da mídia e da propaganda na formação da identidade dos participantes e fatores essenciais para que as pessoas se sintam completas e felizes com seu corpo (CARNIO, 2017).

A partir da nossa leitura sobre o trabalho de Carnio (2017), sintetizamos o resultado de nossa busca para elucidar as compreensões dos professores sobre elementos controversos da questão sociocientífica e os tópicos do Caderno do Aluno identificados por eles. 
Quadro 1 - Controvérsias e conteúdos disciplinares explicitados pelos professores

\begin{tabular}{|c|c|c|}
\hline & $\begin{array}{l}\text { Controvérsia geradora das } \\
\text { atividades de sala de aula }\end{array}$ & $\begin{array}{c}\text { Conteúdos disciplinares identificados no } \\
\text { Caderno do Aluno }\end{array}$ \\
\hline Educação Física & $\begin{array}{l}\text { Não pode ser identificada no relato de } \\
\text { Carnio (2017) }\end{array}$ & $\begin{array}{l}\text { gasto energético; relação entre insulina, glucagon } \\
\text { e metabolização do açúcar; índice de massa } \\
\text { corporal }\end{array}$ \\
\hline Ciências e Biologia & $\begin{array}{l}\text { Emagrecimento por uso de drogas e } \\
\text { saúde do corpo }\end{array}$ & $\begin{array}{l}\text { composição orgânica e atuação dos } \\
\text { medicamentos, anfetaminas e suplementos } \\
\text { proteicos no organismo }\end{array}$ \\
\hline História & $\begin{array}{l}\text { Estereótipos determinados pelo mercado } \\
\text { e evolução da concepção de beleza na } \\
\text { história }\end{array}$ & $\begin{array}{l}\text { análise histórica da mudança de estereótipo, } \\
\text { papel da mídia na construção do ideal de beleza } \\
\text { norte-americano }\end{array}$ \\
\hline Filosofia e Sociologia & $\begin{array}{l}\text { Imposição do corpo perfeito e qualidade } \\
\text { de vida dos alunos }\end{array}$ & $\begin{array}{l}\text { cultura como construto humano; refinamento do } \\
\text { conceito de obesidade; identidade e conciliação } \\
\text { do aluno com seu corpo. }\end{array}$ \\
\hline Matemática & $\begin{array}{l}\text { Imposição do padrão de beleza e } \\
\text { alimentação saudável e qualidade de vida }\end{array}$ & $\begin{array}{l}\text { gráficos, tabelas, funções e equações do segundo } \\
\text { grau }\end{array}$ \\
\hline Língua Portuguesa & $\begin{array}{l}\text { Comercialização da magreza e saúde do } \\
\text { corpo }\end{array}$ & $\begin{array}{l}\text { construção de artigos de opinião, textos } \\
\text { dissertativos e de diversos gêneros }\end{array}$ \\
\hline Geografia & $\begin{array}{l}\text { Comercialização da beleza e saúde do } \\
\text { corpo }\end{array}$ & $\begin{array}{l}\text { influência da globalização na mudança de hábito } \\
\text { das comunidades; influência das multinacionais }\end{array}$ \\
\hline
\end{tabular}

Fonte: produzido pelas autoras a partir das informações contidas em Carnio (2017).

Carnio (2017) esclarece que, nessa rodada de apresentações, sua participação fundamental, na qualidade de pós-graduando, consistiu no zelo pela busca de um fio condutor que pudesse reger as sequências didáticas a serem desenvolvidas nas salas de aula, fazendo recorrentes intervenções de modo que se pudesse manter viva na discussão a tensão entre os saberes curriculares e a intenção de interdisciplinaridade veiculada pela questão sociocientífica.

\section{PGP Paranaíba: procedimentos químicos para o alisamento capilar, especialmente o formol}

A dissertação e a tese de Santos $(2013,2017)$ desenvolveram-se tendo como foco a constituição e na análise o tratamento de QSC no PGP em uma escola situada no município de Paranaíba-MS.

O PGP começou suas atividades em 2012, sendo o vínculo entre o ambiente acadêmico e a educação básica feito por um pós-graduando, durante todo o percurso do seu mestrado e do seu doutorado, além de um professor do ensino básico assim descrito pelo pós-graduando:

[...] é interessante destacar o papel do professor coordenador, licenciado em Física pela UNESP, campus de Ilha Solteira, que viveu um contexto formativo baseado na articulação da pesquisa em ensino com práticas escolares na graduação, o que the permitiu uma experiência formativa que requer retorno, busca pela fonte original daquele prazer em reconhecer-se autor e pesquisador e esta energia foi direcionada para o PGP, desde a sua constituição, até os esforços dispendidos em sustentá-lo e criar contextos problematizadores e criativos (SANTOS, 2017, p. 99-100).

Tendo o pós-graduando e o professor sido alunos do mesmo curso de graduação, a conversa inicial entre eles já pode se dar num contexto que poderia supor um mesmo entendimento amplo sobre os processos educacionais. Assim, ainda no início 
dos trabalhos, durante discussão sobre problemas que cada professor enfrentava em sala de aula, houve reconhecimento e valorização da necessidade de haver um posicionamento crítico frente ao que chamaram de sistema, sendo reconhecido que professor de física que os diálogos estavam efetivamente se apoiando na busca de horizontalidade entre as falas da universidade e da escola (ENCARNAÇÃO; MARTINS; SANTOS, 2019).

Uma peculiaridade deste PGP é a de que, a despeito de outros professores terem entrado e saído do grupo, permaneceram, durante os quatro anos de sua existência, quatro pessoas bastante comprometidas: o pós-graduando, o professor de física, uma professora de história e um professor de química.

Podemos dizer que o início da preparação das sequências didáticas nos PGP foi marcado pelo processo de análise conjunta da realidade escolar. Além disso, o grupo realizou estudos que envolveram não só as QSC, mas, também promoveram discussões relacionadas ao processo de ensino e aprendizagem, à prática pedagógica, às políticas públicas, à cultura escolar, à interdisciplinaridade e aos desafios e possibilidades do trabalho na escola frente aos atravanques sistêmicos (SANTOS, 2013).

Dando sequência ao planejamento, primeiramente foi considerada uma proposta de realização de um questionário a ser respondido pelos alunos, cujo intuito era saber com quais aspectos de Ciência e Tecnologia eles estavam mais familiarizados (SANTOS, 2013).

Em seguida, nas discussões no PG foram surgindo algumas possibilidades de temas que poderiam levar à construção de uma QSC: a utilização de fones de ouvido, o amassado nas latas de conservas de alimentos e o formal nos produtos de alisamento capilar. Os dois primeiros temas, no entanto, configuraram-se apenas como possibilidades transitórias, cumprindo um papel de convite ao grupo para que continuasse a vislumbrar problemáticas sociocientíficas que partissem da consideração de um artefato tecnológico (SANTOS, 2013).

Quando o professor de química propôs a temática do uso do formol para o alisamento de cabelo, ele foi indagado sobre a possibilidade de se formar um cidadão crítico ensinando química, ao que ele respondeu afirmativamente, alegando que fora da escola os alunos têm um mundo ao redor deles que não está fragmentado como na escola. O professor de física reforçou a alegação do colega trazendo uma fala de um aluno sobre a disparidade entre o que se aprende na escola com vida fora dela. Compreendendo a natureza da provocação o professor de química, então, defendeu a validade do tema uso do formol como sendo a utilização do conhecimento científico na vida cotidiana. Por fim, a questão sociocientífica foi definida e intitulada procedimentos químicos para o alisamento capilar, especialmente o formol.

Seguiu-se, então, um período de esforços individuais no aprofundamento da questão. Assim, cada participante fez uma busca de questões importantes a serem compreendidas pelo grupo de modo a poderem avançar no sentido de um fortalecimento de cada um para sustentar situações de diálogo em sala de aula. "Essas decisões fazem parte do processo formativo: pesquisa, reconhecimento das limitações, planejamento, organização, entre outros" (SANTOS; CARVALHO, 2012, p. 24).

Após as fases de formulação da QSC e de aprofundamento dos conteúdos envolvidos, iniciou-se a fase do planejamento da sequência didática, de modo mais ajustado ao que efetivamente o professor pretende desenvolver nas suas salas de aula. 
A elaboração da sequência didática realizada pelo professor de física, em fase ainda de preparação de aula, privilegiou a produção de uma diversificada série de atividades com o objetivo de que os alunos pudessem aos poucos apropriar-se do sentido de questão sociocientífica que estava sendo veiculado. Por meio da alternância de dois tipos de ações complementares previstas para os alunos realizarem em grupo (leitura e discussão de textos em pequenos grupos e atividades investigativas), eles poderiam considerar casos envolvendo perigos, danos e riscos para a vida humana resultantes do desenvolvimento técnico científico na sociedade contemporânea. Assim, em 10 aulas, seriam introduzidas diversas temáticas científico-tecnológicas. Para isso, foram utilizados bulas de remédio e textos de divulgação científica relacionados a controvérsias específicas. Para cada aula planejada, foram indicados os aspectos sociocientíficos que estariam em evidência em cada caso, podendo ser: o desenvolvimento de habilidades argumentativas, a necessidade de os alunos tomarem de posição diante das questões controversas, o papel dos argumentos de autoridade na consolidação de opiniões, questões de natureza da ciência, o caráter controverso do conhecimento científico, o papel da mídia, o papel da embalagem dos produtos industriais, e a percepção de diversas dimensões (social, ético, científico, jurídico, marketing etc.) referentes a um tema sociocientífico.

Quanto às ações previstas para os alunos realizarem, as leituras e discussões de texto em pequenos grupos privilegiavam a entrada de novas informações e de pontos de vista para apreciá-las e as atividades investigativas proporcionavam a busca de aspectos da ciência e tecnologia que permeiam as vidas dos alunos e os possíveis perigos, danos e riscos nos quais eles mesmo pudessem estar implicados. Nesse segundo caso, podemos citar o exemplo da última aula em que, seria proposto que os alunos analisassem vídeos referentes a duas reportagens que retratam os perigos da utilização do formol e as recomendações da ANVISA sobre este assunto. Desse modo, os alunos deveriam identificar pontos principais de cada vídeo, elegendo-os conforme a relevância atribuída a eles pelo grupo. A partir daí, eles constituiriam um objetivo de investigação que fosse próprio do grupo, o que sinaliza para a possibilidade de início de um novo ciclo, uma nova sequência didática aqui não explicitada.

Da mesma forma que ocorreu no caso da sequência didática referente à questão sociocientífica, padrão de beleza, consumismo e saúde, realizada no PGP Arealva, no caso do PGP de Paranaíba, também não temos documentos sobre a fase de desenvolvimento efetivo da sequência didática junto com os alunos na sala de aula. No entanto, a comparação dos dois conjuntos de dados é importante para podermos identificar que aqui está presente uma fase nova, que é aquela em que cada professor do PGP faz o movimento de deduzir das experiências coletivas anteriores aquilo que será o seu caminhar próprio na busca de diálogo com seus alunos sobre uma questão sociocientífica. Além disso, podemos notar que há um paralelo entre o fato de o professor de física investir na criação de bases para que os seus alunos pudessem, ao final da sequência, iniciar um caminho investigativo próprio e o fato de ele mesmo se projetar para além da construção coletiva do grupo. Dessa forma, podemos afirmar que estes relatos evidenciam interconexão entre os caminhos de formação de professores e o processo de constituição de uma sequência didática. 


\section{Desdobramentos do Debate sobre QSC no PGP: interação com o ensino efetivo}

Santos (2013) expôs três etapas iniciais do PGP Paranaíba: "gênese", um período de negociação, esclarecimentos e fala aberta dos participantes sobre o seu mundo; "desenvolvimento", a conquista da consciência de grupo; e, por fim, "constituição de uma QSC", o processo de construção de posicionamento bem fundamentados e maior sofisticação dos diálogos. Dessa forma, situamos nesta terceira etapa, o início da preparação das sequências didáticas analisadas neste trabalho, na medida em que identificamos como seu ponto de partida o processo de constituição das QSC.

Pudemos aqui enfatizar que a orientação básica de um PGP é a de buscar acordos internos sobre o melhor modo de prosseguir com o trabalho individual e coletivo do grupo, tendo como mote o contínuo aprimoramento das competências argumentativas dos participantes. Pudemos identificar que isso implica uma contínua autocompreensão de dois processos de apropriação cultural (HABERMAS, 2002), que então se apresentam à esfera pública interna do grupo: de um lado, a apropriação da vida vivida pelo grupo na escola e na cidade e, de outro, a apropriação da cultura historicamente construída pela humanidade como um todo. De fato, nos processos de constituição de uma QSC dos três casos aqui considerados, estiveram implicados tanto o trabalho de problematização da realidade da escola e da cidade quanto dos estudos da literatura necessários para o entendimento das abordagens científico educacionais implicadas, o que incluí também, e inevitavelmente, a divulgação científica. Entendemos que o acesso da cultura do mundo da vida na escola e da cidade é dado via grupo, não havendo caminhos exclusivamente individuais que o permita.

Nesse contexto é que precisam ser compreendidas as três formulações das QSC obtidas: o uso de agrotóxicos na região de Arealva-SP, padrão de beleza, consumismo e saúde, e procedimentos químicos para o alisamento capilar, especialmente o formol. Em cada uma delas esteve implicada uma controvérsia, na medida em que, por um lado, podem ser identificados elementos da cultura que adentram o grupo tanto a partir do mundo da vida como por meio da literatura (região de Arealva-SP; saúde; alisamento de cabelo) e, por outro, de elementos adversos que somente podem ganhar sentido a partir no momento histórico capitalista em que estamos imersos (agrotóxicos; padrão de beleza e consumismo; procedimentos químicos e formol).

Por outro lado, o desenvolvimento de uma QSC, na sala de aula, também não se dá de modo apartado das contradições da modernidade, o que obriga o professor a retornar periodicamente ao PGP, para encaminhar novas discussões em função dos ajustes à interação com os alunos na sala de aula que se fizerem necessários, na etapa em que ocorrem os desdobramentos individuais das preparações de sequências didáticas.

Pudemos perceber que, se considerarmos o esquema proposto por Santos (2013), esta nova etapa corresponderia a uma quarta etapa do PGP, a qual demarca um período em que se amplia a autonomia do professor diante da QSC, uma vez que ele agora, podendo se perceber reconhecido num grupo, é chamado a articular dois contextos: o de sua formação e o do seu próprio ensinar ciências. Assim, o surgimento desta etapa é permitido tanto pelo processo coletivo que acabou de ocorrer no PGP quanto pela sua aproximação (com ênfase individual) da perspectiva da sua sala de 
aula, a qual envolve também a dimensão curricular. Isso implica um olhar novo para a QSC, uma retomada dela num nível mais elevando da espiral, o que é possibilitado pela reflexibilidade entre as necessidades advindas das compreensões atingidas na etapa anterior e o detalhamento dos conteúdos sociocientíficos agora exigido.

Do duplo processo descrito acima decorre também uma maior profundidade de compreensão da abordagem sociocientífica de um modo geral. Neste aspecto, vale retomar os relatos que compõem o corpus deste trabalho para enumerar características dessa abordagem que pudemos nele identificar: aproximação tanto dos professores como dos alunos de um contexto comunicativo com decorrente desenvolvimento de competências argumentativas; autonomia dos professores e dos alunos na consideração das controvérsias sociocientíficas; a compreensão das relações de poder na consolidação de opiniões; natureza da ciência e o caráter controverso do próprio conhecimento científico; papel fundamental da mídia e da divulgação científica nos processos de formulação de uma QSC; a percepção da multiplicidade de dimensões envolvidas etc.

Paralelamente, as voltas recorrentes dos professores à instâncias de diálogo no PGP, durante os processos individuais de preparação de aulas, permitem novos níveis de compartilhamento da visão do todo envolvido na preparação de sequências didáticas de caráter sociocientífico, o que por sua vez promove o fortalecimento da ideia central do próprio PGP que é a de constituir sua autonomia perante à escola, na qualidade de promotor de cultura e de sociedade na unidade escolar, e perante à instâncias externas a ele, tais como os demais PGP que compõem o GGP.

\section{Considerações Finais}

Pensar o ensino como prática emancipadora a partir da proposta de construção de esferas públicas democráticas nas escolas é algo que o grupo de pesquisa AVformativa tem buscado em suas práticas na interface escola-universidade. Isso se dá como discurso público ligado à igualdade de participação e justiça social, sendo guiado pela ação comunicativa. Por um lado, investe-se em incessante busca de tematização da realidade vivida e, por outro, na restauração de uma comunidade de valores progressistas compartilhados. Nos seus projetos realizados em parceria com a escola, o esforço conjunto de desenvolvimento de sequências didáticas de caráter sociocientífico, as quais estão intimamente relacionadas com o processo de formação dos professores e com os conteúdos curriculares, assume um lugar importante que representa um ponto de partida e um ponto de retorno à realidade escolar.

Ressaltamos aqui a necessidade de ressignificação da ideia de conteúdo de modo a abranger também aqueles implicados na compreensão da ciência em sua relação com a tecnologia, a sociedade e o ambiente. Para Carnio (2017, p. 218), "[...] o fenômeno da aprendizagem, objeto de trabalho do professor, não é fragmentado entre a controvérsia sociocientífica de um lado e a sequência de ensino de outro", o que implica também ligação orgânica entre os conteúdos e as metodologias para o seu ensino nos seus aspectos epistemológico, cognitivo e social, o que permanece sempre em dependência de uma sistematização por parte do professor durante as atividades preparatórias. 
Assim, o exercício argumentativo na busca de definição e tratamento comum (entre professores e entre professores e alunos) de uma controvérsia imersa nos conteúdos perpassa aspectos éticos e morais e impõe uma preocupação com a formação dos alunos para uma atuação político social. A visão de escola como mundo da vida e sistema (LONGHI, 2008) implica em reconhecermos a viabilidade de uma unidade práxica entre a formação dos professores, o trabalho deles com as sequências didáticas e a educação científico tecnológica de seus alunos. Desse modo, cabe-nos, conjuntamente, qualificar as sequências didáticas para reconciliá-las com a vida. Nesse sentido, compreendemos que as sequências didáticas de caráter sociocientífico impõem a necessidade de preparação conjunta de aulas por professores de uma escola.

\section{Agradecimentos}

Agradecemos ao Programa Observatório da Educação da Fundação Coordenação de Aperfeiçoamento de Pessoal de Nível Superior (CAPES).

\section{Referências}

ARENGHI, L. E. B. A divulgação científica no contexto escolar: o ensino de modelos atômicos a partir da temática de agrotóxicos e as implicações / possibilidades para a formação de alunos do ensino médio. 2014. 203 f. Dissertação (Mestrado em Educação para a Ciência) - Faculdade de Ciências, Universidade Estadual Paulista, Bauru, 2014. Disponível em: https://repositorio.unesp.br/ handle/11449/110894. Acesso em: 20 mar. 2021.

CARNIO, M. P. A experiência formativa de professores no trabalho com uma questão sociocientífica: potencialidades e obstáculos em um pequeno grupo de pesquisa. 2017. $314 \mathrm{f}$. Tese (Doutorado em Educação para a Ciência) - Faculdade de Ciências, Universidade Estadual Paulista, Bauru, 2017. Disponível em: https://repositorio.unesp.br/handle/11449/152066. Acesso em: 20 mar. 2021.

ENCARNAÇÃO, D. S.; MARTINS, A. C. R.; SANTOS, P. G. F. A cultura de formação de professores instituída no PGP de Paranaíba e a produção de conhecimentos no tratamento de questões sociocientíficas. In: ORQUIZA DE CARVALHO, L. M.; CARVALHO, W. L. P.; LOPES JÚNIOR, J. (org.). Educação científica em questão: a escola como produtora de cultura e de sociedade. São Paulo: Cultura Acadêmica, 2019. p. 87-116.

FREITAS, Z. L. Um projeto de interação universidade-escola como espaço formativo para a docência do professor universitário. 2008. Tese (Doutorado em Educação para Ciência) - Faculdade de Ciências, Universidade Estadual Paulista, Bauru, 2008. Disponível em: https://repositorio.unesp. br/handle/11449/101996. Acesso em: 21 mar. 2021.

GENOVEZ, L. G. R. Homo magister: conhecimento e reconhecimento de uma professora de ciências pelo campo escolar. 2008. 229 f. Tese (Doutorado em Ensino de Ciências) - Faculdade de Ciências, Universidade Estadual Paulista, Bauru, 2008. Disponível em: https://repositorio.unesp. br/handle/11449/101999. Acesso em: 21 mar. 2021.

GIROUX, H. Os professores como intelectuais: rumo a uma pedagogia crítica da aprendizagem. Porto Alegre: Artes Médicas, 1997.

HABERMAS, J. Racionalidade e comunicação. Lisboa: Edições 70, 2002.

LENHARO, A. F. L. et al. Considerações sobre a formação de professores na interação entre universidade e escola expressa no histórico do pequeno grupo de pesquisa em Arealva - SP. In: ORQUIZA-DE-CARVALHO, L. M.; CARVALHO, W. L. P.; LOPES JUNIOR, J. (org.). Educação científica em questão: a escola como produtora de cultura e de sociedade. São Paulo: Cultura Acadêmica, 2019. p. 73-86. 
LONGHI, J. A. Ação educativa e agir comunicativo. Caçador, SC: Universidade Alto Vale do Rio do Peixe, 2008.

LOPES, N. C. A constituição de associações livres e o trabalho com as questões sociocientíficas na formação de professores. 2013. 389 f. Tese (Doutorado em Educação para a Ciência) - Faculdade de Ciências, Universidade Estadual Paulista, Bauru, 2013. Disponível em: https://repositorio. unesp.br/handle/11449/102061. Acesso em: 21 mar. 2021.

MARTINEZ, C. L. P. Formação de professores e avaliação formativa: análise de um projeto de interação universidade-escola. 2009. Tese (Doutorado em Educação para a Ciência) - Faculdade de Ciências, Universidade Estadual Paulista, Bauru, 2009. Disponível em: https://repositorio. unesp.br/handle/11449/101992. Acesso em: 21 mar. 2021.

MARTÍNEZ-PÉREZ, L. F; CARVALHO W. L. P. Contribuições e dificuldades da abordagem de questões sociocientíficas na prática de professores de ciências. Educação e Pesquisa, São Paulo, v. 38, n. 3, p. 727-741, jul./set. 2012.

ORQUIZA-DE-CARVALHO, L. M. Apresentação. In: ORQUIZA-DE-CARVALHO L. M.; CARVALHO W. L. P.; LOPES JUNIOR, J. (org.). Formação de professores, questões sociocientíficas e avaliação em larga escala: aproximando pós-graduação da escola. São Paulo: Escrituras, 2016. p. 11-18.

ORQUIZA-DE-CARVALHO L. M.; CARVALHO W. L. P.; LOPES JUNIOR, J. (org.). Educação científica em questão: a escola como produtora de cultural e de sociedade. São Paulo: Cultura Acadêmica, 2019.

PEDRANCINI, V. D.; SIERRA, D. F. M. Questões sociocientíficas e formação crítica de professores. In: ORQUIZA-DE-CARVALHO L. M.; CARVALHO W. L. P.; LOPES JUNIOR, J. (org.). Formação de professores, questões sociocientíficas e avaliação em larga escala: aproximando pós-graduação da escola. São Paulo: Escrituras, 2016.

PIGNATI, W. Entenda por que o Brasil é o maior consumidor de agrotóxicos do mundo. [Entrevista cedida a] Mariana Lucena. Galileu, Rio de Janeiro, ago. 2010. Disponível em: https://cutt.ly/ GxWjjUV. Acesso em: 19 mar. 2021.

O QUE você precisa saber sobre comida e agrotóxicos. Veja, São Paulo, ed. 2250, p. 84-88, 4 jan. 2012.

SANTOS, A. M.; CARNIO, M. P.; MENDONÇA, T. Introdução. In: ORQUIZA-DE-CARVALHO L. M.; CARVALHO W. L. P.; LOPES JUNIOR, J. (org.). Formação de professores, questões sociocientíficas e avaliação em larga escala: aproximando pós-graduação da escola. São Paulo: Escrituras, 2016. p. 31-38.

SANTOS, P. G. F. As questões sociocientíficas na formação de professores: o pequeno grupo de pesquisa como comunidade de experiência. 2017. 216 f. Tese (Doutorado em Educação para a Ciência) - Faculdade de Ciências, Universidade Estadual Paulista, Bauru, 2017.

SANTOS, P. G. F. O tratamento de questões sociocientíficas em um grupo de professores e a natureza do processo formativo fundamentado em uma perspectiva crítica. 2013. 209 f. Dissertação (Mestrado em Educação para a Ciência) - Faculdade de Ciências, Universidade Estadual Paulista, Bauru, 2013.

SANTOS, P. G. F.; CARVALHO W. L. P. A constituição de uma questão sociocientífica em um grupo de professores: um processo polifônico de desvelamento da realidade concreta. Amazônia, Belém, v. 9, n. 17, p. 1-26, jul./dez. 2012.

SANTOS, P. G. F.; CARNIO, M. P. Apresentação: a universidade e a escola elaborando a contrapelo. In: ORQUIZA DE CARVALHO, L. M.; CARVALHO, W. L. P.; LOPES JÚNIOR, J. (org.). Educação científica em questão: a escola como produtora de cultura e de sociedade. São Paulo: Cultura Acadêmica, 2019. p. 13-22.

ZABALA, A. A prática educativa: como ensinar. Porto Alegre: Artes Médicas Sul, 1988. 